\title{
Characterization and Transferring of Human Rotavirus Double-Layered Particles in MA104 Cells
}

\author{
Ali Teimoori ${ }^{1} ;$ Hoorieh Soleimanjahi ${ }^{1,} ;$ Manoochehr Makvandi $^{2}$ \\ ${ }^{1}$ Department of Virology, Faculty of Medical Sciences, Tarbiat Modares University, Tehran, IR Iran \\ ${ }^{2}$ Department of Virology, Ahvaz Jundishapur University of Medical Sciences, Ahvaz, IR Iran \\ ${ }^{*}$ Corresponding author: Hoorieh Soleimanjahi, Department of Virology, Faculty of Medical Science, Tarbiat Modares University, Tehran, IR Iran. Tel/Fax: +98-2182883561, E-mail: \\ soleim_h@modares.ac.ir \\ Received: January 22, 2013; Revised: April 25, 2013; Accepted: June 1, 2013
}

\begin{abstract}
Background:Rotavirus(RV)is a major cause of gastroenteritis ininfants and children and is one of the most severe public health problems. Rotaviruses outer layer contains two proteins including VP4 and VP7. These proteins are necessary for host-cell binding and penetration. TLP (triple layer virus particle) of RV is a complete infectious virion that binds to the target cells and internalized at the cytoplasm. The DLP (double layer virus particle) is a non-infectious particle that is formed through exclusion of the outer layer proteins including VP4 and VP7. These DLPs are the transcriptionally active forms of rotavirus.

Objectives:The aim of this study was to transfer DLP of RV into cytoplasm of MA104 cells by Lipofectamine and to analyze their replication. Materials and Methods: Initially, rotavirus was purified by CsCl discontinuous gradient and DLP was separated from TLP based on density differences. For confirmation, sodium dodecyl sulfate polyacrylamide gel electrophoresis(SDS-PAGE) of the proteins were conducted Then the purified DLP of RV was transferred into MA104 cells using Lipofectamine.

Results: We attempt to avoid the attachment and entry of the rotavirus by using Lipofectamine to mediate the delivery of viral particles directly into the cytoplasm. DLP was endocytosed into the cytoplasm following treatment by Lipofectamine and then replicated in cytoplasm.

Conclusions: Therefore the non-infectious DLPs were became infectious if introduced into the cytoplasm of permissive and cancerous cells, without passing attachment and entry process.

Keywords:Rotavirus; Transfection; Viral Plaque Assay
\end{abstract}

\section{Background}

Rotavirus (RV) is a major cause of gastroenteritis in infants and children and is one of the most severe public health problems, worldwide especially in developing countries of Africa and Asia continents (1). Two rotavirus vaccines, which are licensed in the United States are RotaTeq ${ }^{\circledR}$ and Rotarix ${ }^{\circledR}$. These rotavirus vaccines are safe and effective to prevent severe diarrhea (2). Rotaviruses have a segmented genome packaged within a triple layer virus particle (TLP). The outer layer of the virion contains two proteins including VP4 and VP7 (3). These proteins are molecular machinery for host-cell binding and penetration. VP4 and VP7 are a set of spike-like projections and a shell, respectively. The intermediate layer of rotavirus capsid composed of 260 trimer of VP6 proteins and the inner layer is composed of 120 molecules of VP2 (4).

Several molecules including gangliosides GM1, GM3, integrins and heat shock cognate protein 70 have been involved as attachment receptors for rotaviruses $(5,6)$. In cell culture, rotavirus showed two forms of triple layer and double layer particles (DLP). TLP of RV is complete in- fectious virion and binds to target cells, which internalized at the cytoplasm. The DLP is a noninfectious particle which forms through removal of the outer layer proteins (VP4 and VP7). These DLPs are transcriptionally active forms of rotavirus and capable to produce virus within the target cells (7). Since non-treated DLPs cannot internalize to the target cells. In this study, DLP of human rotavirus RV4 purified with $\mathrm{CsCl}$ and transfected with Lipofectamine ${ }^{\circledR}$. For confirmation of virus biological activity and virus production the plaque assay was done. By the use of Lipofectamine, Transferring of non-infectious DLPs in target cells mimic native rotavirus infection and may be used for the treatment of cancerous cells.

\section{Objectives}

In this report we showed that the DLP particles are transferred by treating with transfectant reagents such as Lipofectamine, which they can be internalized into several kinds of nonpermissive mammalian cells as well as cancerous cells for oncolytic purpose.

Implication for health policy/practice/research/medical education:

The application of transfection methods is an imperative tool to investigate the gene-based construct function for diagnostic and research purposes. Penetration of rotavirus TLP into the target cells took place in infected cells but double layered particle (DLP) are disable to attach. It can be replicable while transfecting into the cytoplasm.

Copyright (C) 2014,Ahvaz Jundishapur University of Medical Sciences; Published by Kowsar Corp. This is an open-access article distributed under the terms of the Creative Commons Attribution License, which permits unrestricted use, distribution, and reproduction in any medium, provided the original work is properly cited. 
Teimoori A et al.

\begin{tabular}{|c|c|c|c|}
\hline- & Component & 6 Well Plate for Test & 6 Well Plate for Control of Trasfection \\
\hline 1 & DMEM (High glucose) & $890 \mathrm{uL}$ & $890 \mathrm{uL}$ \\
\hline 2 & Lipofectamine 2000 Reagent & $4,6,10 \mathrm{uL}$ & - \\
\hline 3 & Number of cells & $5 \times 10^{5}$ & $5 \times 10^{5}$ \\
\hline 4 & DLP purified & $100 \mathrm{uL}$ & $100 \mathrm{uL}$ \\
\hline 5 & \multicolumn{3}{|c|}{ Mixed 1, 2 and 4, Incubated for 5 minutes at room temperature } \\
\hline 6 & \multicolumn{3}{|c|}{ Mixed component tenfold diluted $\left(10^{-1}\right.$ to $\left.10^{-6}\right)$ into MA104 confluent cells incubated at $37^{\circ} \mathrm{C}$} \\
\hline
\end{tabular}

\section{Materials and Methods}

\subsection{Virus and Cells}

MA104 cells (Pasture, Iran) were cultured in $175-\mathrm{cm}^{2}$ flask containing DMEM (DMEM, Gibco) supplemented with $10 \%$ fetal bovine serum (FBS) at $37^{\circ} \mathrm{C}$ and $5 \% \mathrm{CO} 2$. Confluent Monolayers of MA104 cells were infected with human rotavirus RV4 at a multiplicity of infection (MOI) of 0.05 . For virus activation, trypsin (porcine pancreatic type IX: Sigma) at a final concentration of $10 \mu \mathrm{g} / \mathrm{mL}$ was added and incubated for 1 hour at $37^{\circ} \mathrm{C}(8)$. The infected cells were lysed through three freezing-thawing cycles in order to release cell associated virus.

\subsection{DLP Purification}

Discontinous isopycnic density-gradient centrifugation was established for purification of rotavirus. Two forms of RV particles have been observed using $\mathrm{CsCl}$ gradient $(8,9)$. The density of TLP and DLP were $\sim 1.36$ $\mathrm{g} / \mathrm{cm} 3$ and $\sim 1.38 \mathrm{~g} / \mathrm{cm}^{3}$, respectively. Two hundred milliliters of rotavirus cell lysate centrifuged at $110000 \times$ g, at $4^{\circ} \mathrm{C}$ for 1.5 hours using an SW28 rotor in order to precipitate the virus particles and cellular debris, then the pellet resuspended in $40 \mathrm{~mL}$ of Tris sodium chloride (TNC) buffer (20 mM, Tris.Cl, $100 \mathrm{mM} \mathrm{NaCl,1} \mathrm{mM} \mathrm{CaCl} 2$ ). Resuspended solution were mixed with an equal volume of Freon (Trichlorotrifluoroethane) and centrifuged at $4100 \times \mathrm{g}$ at $4^{\circ} \mathrm{C}$ for 10 minutes. Upper phase of solution transferred into tubes and centrifuged at $110000 \times \mathrm{g}$, at $4^{\circ} \mathrm{C}$ for 1.5 hours using an SW28 rotor to pellet virus particles. Virus pellet suspended in $6 \mathrm{~mL}$ of TNC buffer. The discontinuous gradient density of $1.4 \mathrm{~g} /$ $\mathrm{cm} 3 \mathrm{CsCl}$ for lower phase and $1.2 \mathrm{~g} / \mathrm{cm}^{3} \mathrm{CsCl}$ for upper phase was prepared and virus suspension poured and centrifuged at $110000 \times \mathrm{g}$, at $4^{\circ} \mathrm{C}$ for 3 hours using a 50 Ti rotor. The two cloudy bands have been shown. Upper and lower bands are infectious triple-layered and noninfectious DLPs, respectively. The DLP band was isolated and then the $\mathrm{CsCl}$ was eliminated by dialyzing against TNC buffer containing 0.5 M Ethylene diamine tetraacetic acid (EDTA), overnight (8).
3.3. Sodium Dodecyl Sulfate Polyacrylamide Gel Electrophoresis (SDS-PAGE) of Double Layer Particle (DLP) and Triple Layer Particle (TLP)

The purified DLP and TLP of viruses were resuspended individually with $5 \mathrm{X}$ sample buffer (Fermentas). The samples were immediately denatured prior to use by incubating at $95^{\circ} \mathrm{C}$ for 5 minutes in the presence of $\beta$-mercaptoethanol. Proteins were resolved on $12 \%$ SDSPAGE (Laemmli system) and visualized by Coomassie Blue R-25 0.1\% stain.

\subsection{Triple Layer Particle (DLP) Transfection}

The purified DLP was mixed with Lipofectamine and transfected into MA104 cells. As a control of experiment, DLP without Lipofectamine was serially diluted $\left(10^{-1}\right.$ to $10^{-}$ $\left.{ }^{6}\right)$ and transfected into cells using the same protocol. To minimalize the toxicity to the cells and efficient lipofection of viral particles, the amount of Lipofectamine was optimized based on the manual of Lipofectamine 2000 Reagent. Three concentrations of the transfectant with DLP of RV were applied (Table 1 ).

\subsection{Plaque Assay}

The plaque assay is one of the common biological assays using for the quantification of RV. This assay is based on the CPE, which was caused by active and replicapable forms of RV in cultured cells and introduced to plaqueforming units per milliliter of virus (PFU/mL). Neutral red was used as a vital stain for visualization of the plaques. The living cells uptake the neutral red, whereas the lysed infected cells are transparent and form the plaque (without uptake of neutral red) $(10,11)$ After transfection the agar containing 1:1 mixture of 1.6\% (w/v) agar and serumfree $2 \times$ DMEM was overlaid. Once the agar was solidified, the plates were transferred to a $37^{\circ} \mathrm{C}$-incubator until plaques are visible. The same procedure was applied for control of experiment.

\section{Results}

\subsection{Propagation of Rotavirus in MA104 Cells}

For RV propagation, infections are commonly per 
Figure 1. Infected and Non Infected MA104 Cells

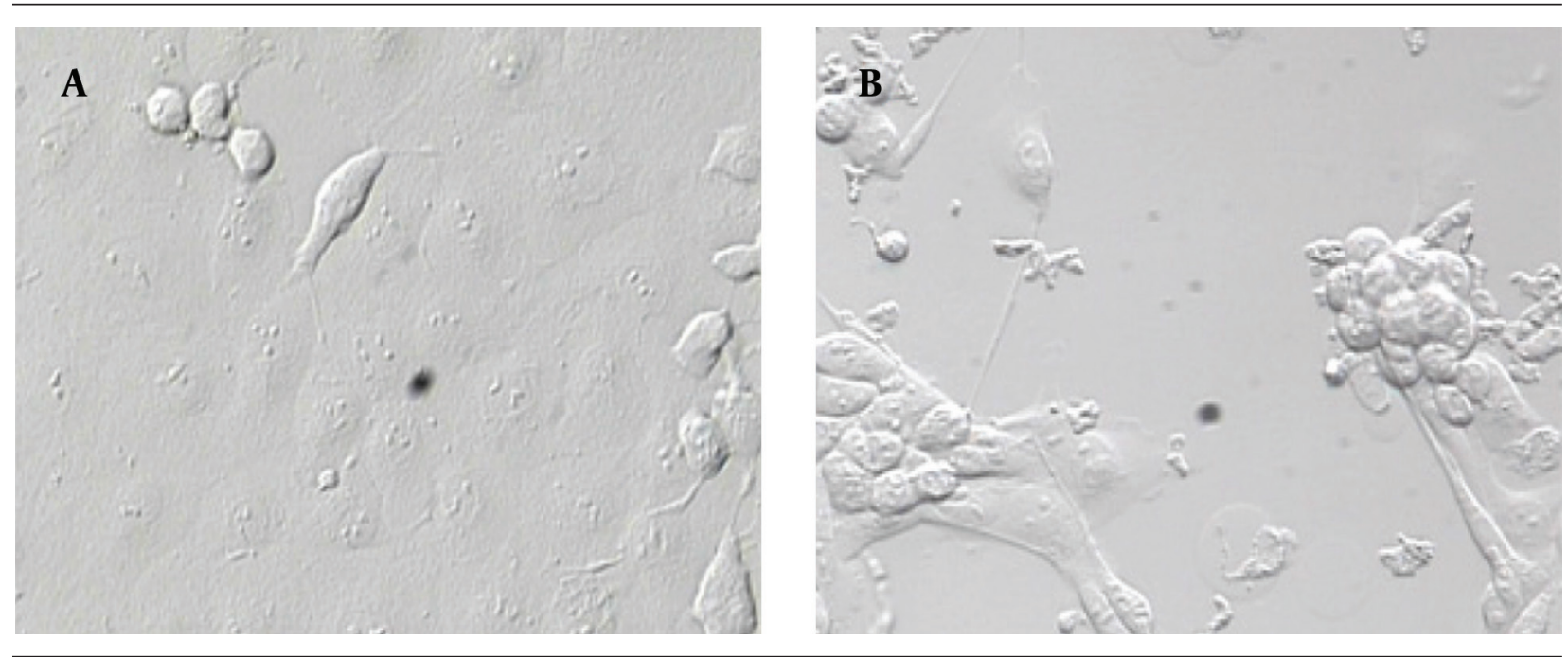

A: confluent monolayer noninfected MA104 cells; B: infected MA104 cells and CPE.

Figure 2. Two Distinct Bands of RV Particles Using a CsCl Gradient

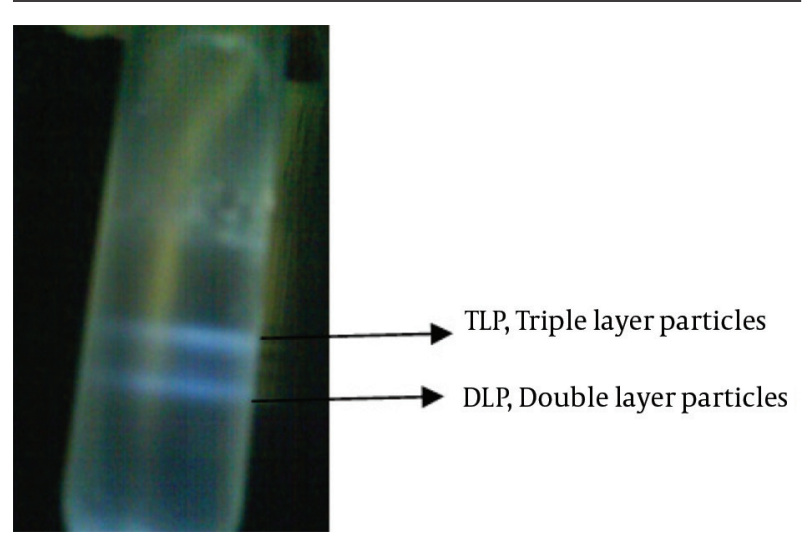

The upper band compromises of infectious, triple-layered particles (TLPs; density $1.36 \mathrm{~g} / \mathrm{cm}^{3}$ ) and the lower one compromises of noninfectious, double-layered particles (DLPs; density $1.38 \mathrm{~g} / \mathrm{cm}^{3}$ ).

formed at low MOI (0.05) to reduce the generation of mutations, gene rearrangements and to optimal yields of infectious virus. CPE has progressed to fully disrupt, three days after infection with human rotavirus RV4 (Figure 1). Rotavirus was released by the lysis of MA104 infected cells and total cell lysate and medium was collected.

\subsection{Double Layer Particle (DLP) Purification of Hu- man Rotavirus}

Centrifuged tube was contained two cloudy, whitishcolored bands which was visible in darkened room with an inverted light source. The upper phase of band was discarded by a pipet for collection of TLP and DLP bands separately in two individual tubes (Figure 2). To remove the probable trace of TLP, 10 mM EDTA was added to the dialysis buffer.

\subsection{Protein Content Analysis of TLP \& DLP by SDS- PAGE}

To verify the absence of outer capsid proteins in DLP, the treated band was analyzed by SDS PAGE. In addition TLP was determined as a control of outer capsid protein. Outer capsid proteins consist of VP7 (MW: $38 \mathrm{kDa}$ ) and VP4 (MW: $88 \mathrm{kDa}$ ). In this study, the analysis of the TLP polypeptides pattern revealed the expected pattern of trypsin-treated rotavirus with cleavage of VP4 to yield VP5 (MW: $60 \mathrm{kDa}$ ) and VP8*(MW: $28 \mathrm{kDa})(12)$. Figure 3 was compatible with other researches' findings. The DLP is composed of the remaining four structural proteins including VP1 (MW: $125 \mathrm{kDa}), \mathrm{VP} 2$ (MW: $102 \mathrm{kDa}), \mathrm{VP} 3$ (MW: $88 \mathrm{kDa})$ and VP6 (MW: 44) (7, 13), is shown in Figure 4.

\subsection{Plaque Assay as a Biological Method for Virus Replication}

The plaque assay is the most elegant, quantitative, and useful biological assay for viruses. Four to five days after DLP inoculation, plaques are visible (Figure 5). As control, DLP without transfectant was inoculated and plaque was not visible (Figure 6). Taken together, transferring of DLP into the cytoplasm resulted in production of virus progenies and replication of virus resumed.

\section{Discussion}

Rotaviruses are non-enveloped viruses that infect enterocytes in small-intestinal and entirely replicate in the cell cytoplasm $(1,14)$. Rotavirus particles consist of three 
Teimoori A et al.

Figure 3. Electrophoretic Pattern of Triple Layer Particle \& Double Layer Particle
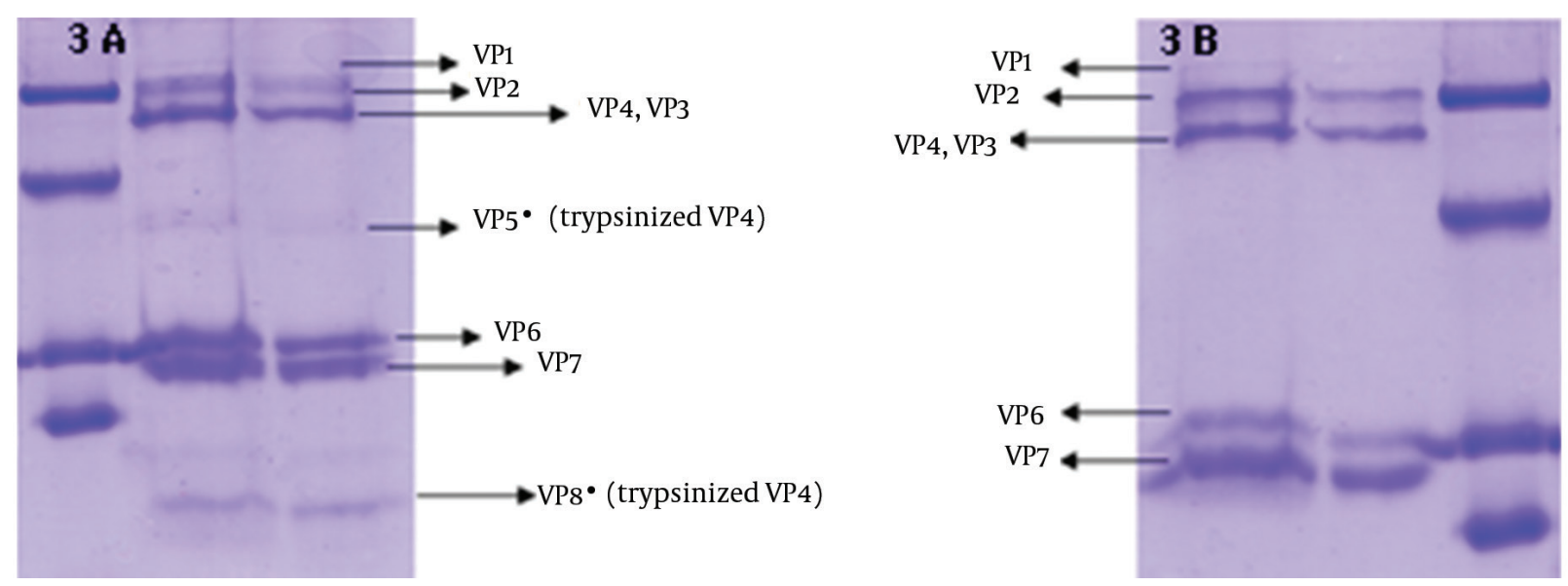

A: TLP of trypsinized human rotavirus particle in which the VP4 protein was cleaved to VP5* and VP8*; B: TLP of not trypsinized human rotavirus with an intactVP4.

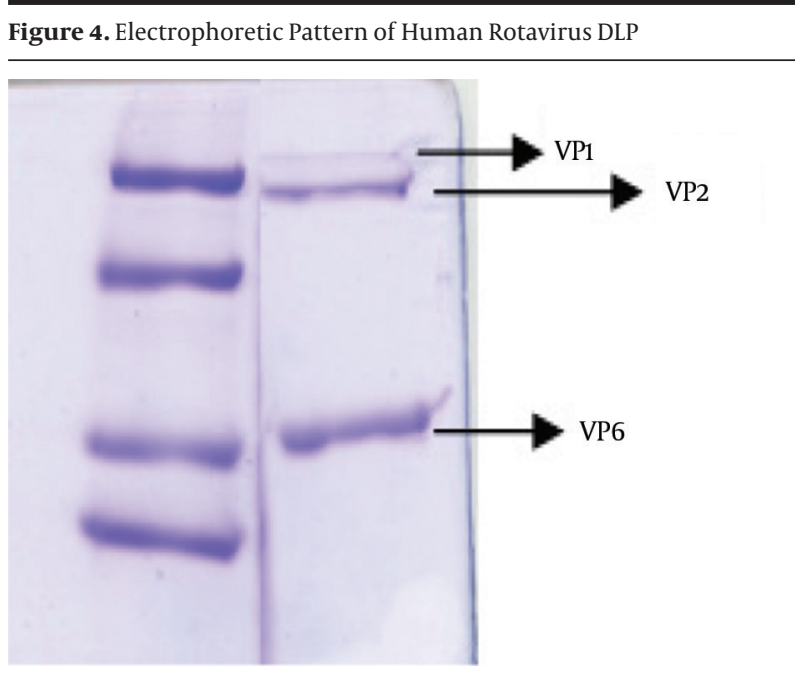

DLP of human rotavirus containing of four proteins including VP1, 2, 3 and VP6, traces mounts of VP3 and not detected by Coomassie Blue staining.

concentric layers of protein or triple layered particles (TLP), which is composed of two proteins, VP4 and VP7, in its outer layer. The rotavirus virion attaches to the target cell receptor through VP8* (produced by the cleavage of VP4 into VP5* and VP8*). The mechanism of rotaviruses entry to cells remains controversial and different pathway for virus entry has been presented in several published researches $(15,16)$. Calcium-dependent, clathrin-coated, caveolae-mediated endocytosis and direct penetration are suggested methods of virus entry, but further detailed studies are required to understand this pathways (17). However, some of these studies using specific inhibitory drugs have definitely ruled out the classical endocytic mechanism of trypsin-primed rotavirus.

Despite some contradictory results, the prevailing concept from these studies shows rapid kinetics of internal- ization enters through direct penetration, leading to a productive infection by enzymatic treatment. Trypsinactivated Rotaviruses was internalized within a few minutes (half-time of 3 to 5 minutes) $(18,19)$. Following penetration into the target cells, the outer capsid is loosed and the double-layered particle (DLP) released into the cytosol. Subsequently the internal polymerase complex activates (VP1 and VP3) to transcribe capped positivesense RNA ((+) RNAs) from each of the 11 double-stranded RNA (dsRNA) segments $(20,21)$.

In this experiment, rotavirus was purified by $\mathrm{CsCl}$ discontinuous gradient. Buoyant density in $\mathrm{CsCl}$ gradient of rotavirus DLP and TLP is different, two kinds of particles were separated and purified. Since DLPs are heavier and denser than TLPs, they move faster than TLPs in $\mathrm{CsCl}$ gradient. The DLP are non-infectious and disable to attach and entre, but these particles can be active and replicapable in the cytoplasm. Polycations as well as Lipofectamine have been shown to increase the infectivity of several viruses and refinement of virus entry $(22,23)$.

In this study, we attempt to bypass the attachment and entry of the rotavirus by using Lipofectamine to mediate the delivery of viral particles directly into the cytoplasm. Probably the DLPs enter into the cytoplasm following treatment by Lipofectamine. Plaque assay is used for confirmation of virus replication, production and biological activity. Based on the results, the treatment of DLPs with Lipofectamine does not have influence on virus replication. For verification of DLP purity, SDS-PAGE was applied and VP6, VP1, 2 proteins have been detected. In DLP, VP6 is the major constituent with 260 trimers of VP6 protein. As shown in previous experiments, the transfer of DLP in non-permissive cell lines could mediate infection (3) and perhaps this method can be used for the transfer of rotavirus DLP in non-permissive and cancerous cells for oncolytic purposes. 
Figure 5. Results of Plaque Assay Using the DLP of Rotavirus Showing the Transfer of the Particles Into Permesive MA104 Cells

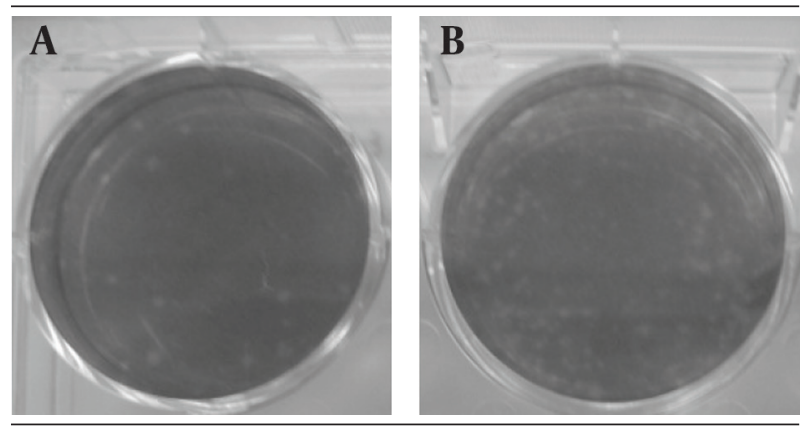

At 96 hours of post-infection, the cells were stained with neutral red. A tenfold dilution $\left(10^{-4}\right)$ of DLP treat with transfectant; B: $10^{-3}$ of DLP treats with transfectant.

Figure 6. Plaque Assay by DLP Without Transfectant

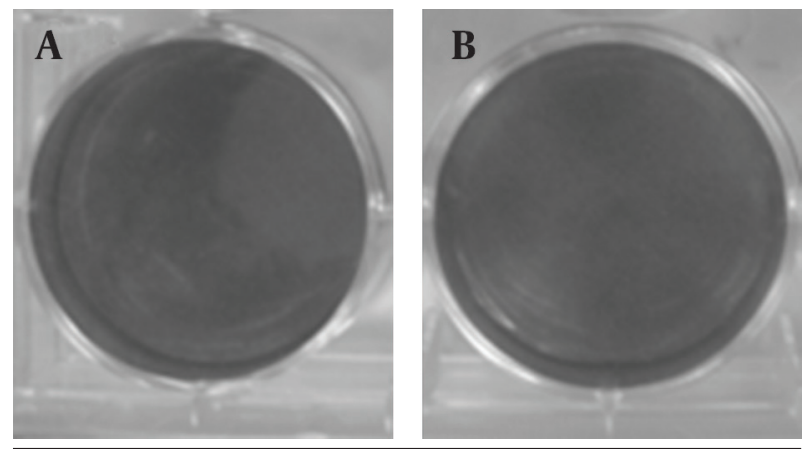

A: Tenfold dilution $\left(10^{-4}\right)$ of DLP without transfectant; B: $10^{-3}$ DLP without transfectant.

\section{Funding Support}

This study was supported by Faculty of Medical Sciences of Tarbiat Modares University.

\section{References}

1. Tate JE, Burton AH, Boschi-Pinto C, Steele AD, Duque J, Parashar UD, et al. 2008 estimate of worldwide rotavirus-associated mortality in children younger than 5 years before the introduction of universal rotavirus vaccination programmes: a systematic review and meta-analysis. Lancet Infect Dis. 2012;12(2):136-41.

2. Glass RI, Parashar UD, Bresee JS, Turcios R, Fischer TK, Widdowson MA, et al. Rotavirus vaccines: current prospects and future challenges. Lancet. 2006;368(9532):323-32.

3. Settembre EC, Chen JZ, Dormitzer PR, Grigorieff N, Harrison
SC. Atomic model of an infectious rotavirus particle. EMBO J. 2011;30(2):408-16.

4. McClain B, Settembre E, Temple BR, Bellamy AR, Harrison SC. Xray crystal structure of the rotavirus inner capsid particle at $3.8 \mathrm{~A}$ resolution. J Mol Biol. 2010;397(2):587-99.

5. Hewish MJ, Takada Y, Coulson BS. Integrins alpha2beta1 and alpha4beta1 can mediate SA11 rotavirus attachment and entry into cells. J Virol. 2000;74(1):228-36.

6. Graham KL, Halasz P, Tan Y, Hewish MJ, Takada Y, Mackow ER, et al. Integrin-using rotaviruses bind alpha2beta1 integrin alpha2 I domain via VP4 DGE sequence and recognize alphaXbeta2 and alphaVbeta3 by using VP7 during cell entry. J Virol. 2003;77(18):9969-78.

7. Jayaram H, Estes MK, Prasad BV. Emerging themes in rotavirus cell entry, genome organization, transcription and replication. Virus Res. 2004;101(1):67-81.

8. Arnold M, Patton JT, McDonald SM. Culturing, storage, and quantification of rotaviruses. Curr Protoc Microbiol. 2009;Chapter 15:Unit 15C 3.

9. Fang ZY, Glass RI, Penaranda M, Dong H, Monroe SS, Wen L, et al. Purification and characterization of adult diarrhea rotavirus: identification of viral structural proteins. JVirol. 1989;63(5):2191-7.

10. Repetto G, del Peso A, Zurita JL. Neutral red uptake assay for the estimation of cell viability/cytotoxicity. Nat Protoc. 2008;3(7):1125-31.

11. Smith EM, Estes MK, Graham DY, Gerba CP. A plaque assay for the simian rotavirus SAII.J Gen Virol. 1979;43(3):513-9.

12. Prasad BV, Burns JW, Marietta E, Estes MK, Chiu W. Localization of VP4 neutralization sites in rotavirus by three-dimensional cryoelectron microscopy. Nature. 1990;343(6257):476-9.

13. McDonald SM, Patton JT. Rotavirus VP2 core shell regions critical for viral polymerase activation. JVirol. 2011;85(7):3095-105.

14. Lopez S, Arias CF. Multistep entry of rotavirus into cells: a Versaillesque dance. Trends Microbiol. 2004;12(6):271-8.

15. Baker M, Prasad BV. Rotavirus cell entry. Curr Top Microbiol Immunol. 2010;343:121-48.

16. Chemello ME, Aristimuno OC, Michelangeli F, Ruiz MC. Requirement for vacuolar $\mathrm{H}+$-ATPase activity and $\mathrm{Ca} 2+$ gradient during entry of rotavirus into MA104 cells. JVirol. 2002;76(24):13083-7.

17. Sanchez-San Martin C, Lopez T, Arias CF, Lopez S. Characterization of rotavirus cell entry. JVirol. 2004;78(5):2310-8.

18. Dimitrov DS. Virus entry: molecular mechanisms and biomedical applications. Nat Rev Microbiol. 2004;2(2):109-22.

19. Kaljot KT, Shaw RD, Rubin DH, Greenberg HB. Infectious rotavirus enters cells by direct cell membrane penetration, not by endocytosis. J Virol.1988;62(4):1136-44.

20. McDonald SM, Patton JT. Assortment and packaging of the segmented rotavirus genome. Trends Microbiol. 2011;19(3):136-44.

21. Trask SD, McDonald SM, Patton JT. Structural insights into the coupling of virion assembly and rotavirus replication. Nat Rev Microbiol. 2012;10(3):165-77.

22. Kooi C, Mizzen L, Alderson C, Daya M, Anderson R. Early events of importance in determining host cell permissiveness to mouse hepatitis virus infection. J Gen Virol.1988;69 ( Pt 6):1125-35.

23. Bailey CA, Miller DK, Lenard J. Effects of DEAE-dextran on infection and hemolysis by VSV. Evidence that nonspecific electrostatic interactions mediate effective binding of VSV to cells. Virology. 1984;133(1):111-8. 